\title{
Introduction
}

\section{Capacity Building in Ethnographic Comparison}

\author{
Rachel Douglas-Jones, IT University of Copenhagen \\ Justin Shaffner, The New Centre for Research and Practice
}

\begin{abstract}
Capacity building is a pervasive idea that has received little critical treatment from anthropology. In this introduction, we outline the growing use of the idea of 'capacity building' within and beyond development settings, and highlight mechanisms by which it gains footholds in both policy and practice. This special issue centres and questions its histories, assumptions, intentions and enactments in order to bring ethnographic attention to the promises it entails. By bringing together cases from different sectors and continents, the collection pursues capacity building's self-evident character, opening up what capacities themselves are thought to be. By not taking capacity building's promises for granted, the articles collected here have two aims: to interrogate the means of capacity building's ubiquity, and to develop critical purchase on its persuasive power.
\end{abstract}

Keywords: capacity, comparison, development, hope, improvement, insufficiency

On a single day in July 2015, three very different activities around the world were reported in newspapers as 'capacity building' initiatives: policemen in Pakistan learning from university technicians how to handle novel explosive devices were having their capacity built; ${ }^{1}$ so too were farmers in the Marshall Islands as they studied PowerPoints on resilient agricultures; ${ }^{2}$ and even Chinese corporate representatives from the energy sector were building capacity as they convened in Beijing to relate renewable energy to climate change goals. ${ }^{3}$ Capacity building is a central concept in many projects that come under anthropological scrutiny, from institution building and national development projects to individual and community initiatives. It is full of hope and potential, yet also operates from perceptions of insufficiency or absence, summoned because the future it works towards is seen as more desirable than the present. This special issue brings capacity building into ethnographic focus. We use the tension between hope and insufficiency at work in capacity building to explore its intended and unintended effects. Since neither the term nor the practices it engenders have been systematically examined or theorized within the social sciences, we here bring together articles that ethnographically examine how and where the concept is put to work. Through 
comparison of cases from different sectors and continents, the collection questions capacity building's ubiquity and self-evident character, opening up along the way what capacities, human or otherwise, are thought to be. By not taking capacity building's promises for granted, the collected articles advance our understanding of its ubiquity and develop anthropological purchase on its persuasive power.

In this introduction, we outline the history of capacity building within development, before showing its transition to a rich life of its own in the lexicons of government, religious organizations, environmental campaigns, biomedical trainings and more. We offer a thematic framing of the special issue contributions, which are based on ethnographic fieldwork in settings as diverse as Bolivia, Brazil, Cambodia, Ghana, Haiti, Peru, the Philippines, Russia and the United States. Each article is ethnographically specific, yet the effect of reading them alongside one another captures capacity building's mobile character, and points to the political consequences of the malleability evidenced in the opening news stories. A comparative approach provides an opportunity to theorize the concept's emergence and ubiquity at this particular historical moment, where what we might call 'conceptual borrowing' or 'templating' (Simpson 2012: 157) is happening rapidly, and on a global scale (Ong and Collier 2005). Terms from one sector arise in another: collaborations and agreements, for example, push the repeated use of 'partnership' (Jensen and Winthereik 2013), or Christian activities spread notions of 'sin' and 'redemption' (Robbins and Engelke 2010; Cannell 2006), which get transformed through divergent use. We use this broader observation as an entry point to a theoretical discussion that highlights the challenges the widespread use of 'capacity building' poses for analysis. If audit receives attention as a pervasive governing technology (Shore and Wright 2015), should not capacity building also be examined as a mode of thinking and analysis that makes particular political actions seem reasonable and justified' (Merry 2015: 435)? We emphasize three areas of engagement. First, how do we theorize capacity building as a concept and practice constrained neither by cultural or geopolitical region, nor by classical thematic divisions within anthropology? Second, who gets to define capacities - as present, lacking or needing to be built? How do these claims gain legitimacy? Finally, what strategies are available to us as anthropologists to analytically address the way those who use capacity building conceptualize and enact change? Let us begin by providing a brief genealogy of capacity building.

\section{Approaching capacity}

Though the term capacity building is now familiar, it entered development terminology in the late 1980s and early 1990s (Eade 1997), when 'capacity' became tied to terms of improvement like 'strengthening', 'enhancement' and 'development' itself (FudukaParr et al. 2002; United Nations Development Programme [UNDP] 1995, 1998, 2003). The new term appeared to leave some commentators almost breathless with a sense of possibility. Take this description of the 'spiral' model of capacity building from the late 1990s, which

assumes that behind every new latrine, weaving room, or irrigation canal in a village, for example, there are less visible but equally important changes in individual and group knowledge, attitudes and skills. (Robinson and Cox 1998: 127) 
In this unsited description of 'village life', we encounter a capacity building that locates measurable efficacy in material artefacts - latrines and weaving rooms - yet opens towards less visible capacities such as 'knowledge'. The duality comes from the way capacity building can be put to work as both an approach and an objective, as a set of methodologies towards a goal and itself a measurable outcome (Bolger 2000: 1). As mode and goal, what capacity building targets may be anything from 'abilities' to 'understandings, attitudes, values, relationships, behaviours, motivations, resources and conditions' (Bolger 2000: 2). Given such an all-encompassing mandate, it is little wonder that capacity building has been critiqued within development discourse for its vagueness: it is 'elusive' (Kaplan 2000: 517), 'ambiguous' (Black 2003: 116), 'elastic' (Lusthaus et al. 1999: 3) or worse, a 'sloppy piece of aid jargon' (Eade 2010: 204). Given its generic character, commentators wonder: which capacities are desired? Where should efforts be targeted?

These questions are asked by many practitioners. Capacity building emerged during a time when top-down development strategies were being dismantled, with 'partnership' and 'dialogue' promoted as a shift away from hierarchical language (Linnell 2003). Thus, the questions it elicited - about which capacities, and whose - were imagined as part of an open conversation between those who sought to intervene and those who stood as partners or participants in such projects. Capacity building was seen to take into account paradigm shifts towards 'local ownership' of initiatives (Organisation for Economic Cooperation and Development [OECD] 1996) as well as a growing recognition of the role 'external factors in the broader environment' play in the 'capacity of an individual, team, organisation or system' (Milèn 2001: 2). Attending to a broader environment, in turn, involved the dismantling of a further dominant association of capacity with what were termed 'technical competences'. By 1996, critiques of a 'technical' mindset had taken hold, with increasing acknowledgement that capacity meant more than mere technical competence. 'The international development community was mistaken', Lusthaus et al. (1999: 19) remarked cuttingly, 'when it thought that the technologies required to build a bridge were the same as those required to build a society - civil or otherwise'. Amidst these changes, however, calls for capacity building continued to grow. Towards the end of the 1990s, Deborah Eade, a prominent commentator on capacity building, noted that 'no UN Summit goes by without ritual calls for capacity building programmes for NGOs' (Eade 1997: 1). More than a decade on, her comment remained apposite: the Accra Agenda for Action (OECD 2008) adopted in 2008 foregrounds capacity development, as do the UN's Millennium Development Goals (UNMDG 2013).

Even in this thumbnail sketch, it is evident that the rhetoric of capacity building has been caught between - and captured the imagination of - different movements in policy and become enrolled into quite different forms of political service. As structural adjustment policies shrank the state and downplayed institutions, capacity building became a tool to attend to individuals and their capacities. Through these shifting eras, definitional clarity remained elusive. As a result, those using the term go to some lengths to pin it down and organize its conceptual landscape - in rapidly proliferating new configurations. We find capacities arranged by 'levels' and 'types', separated into 'functional and technical' (UNDP 2009), 'soft' elements (motivational and process) and 'hard' elements (technical) (Land 1999). From defining capacities to 
building them, practitioner authors offer key steps to success, from initial stakeholder engagement to end of project evaluation. For this reason, Chris Roche of Oxfam sets up capacity building as a concept to be tested (Roche 1997: v), measured against a goal, marking an alignment with policy orientations wherein capacities are 'most usefully assessed in relation to their development purpose' (Malik 2002: 27). The question of 'which capacities' is transformed into a concern about 'which ends', opening new sets of disagreements of what capacity building might ultimately be 'for'.

Amidst this disagreement, change is given central importance. 'Whether they are aware of it or not', write Lusthaus et al., 'those involved in the field of capacity development are engaged in trying to understand and predict change' (1999: 10). They are also trying to bring it about. Commentators emphasize the importance of a 'baseline' from which change can be measured, anxieties arising about 'pejorative' assumption of deficits entailed (Linnell 2003). Yet once insufficiencies have been defined and a plan drawn up, implementation is key, the express aim being as explicit as 'chang[ing] a society's rules, situations and standards of behaviour' (Morgan and Qualman 1996: n.p.). A focus on change places capacity building alongside ideas that aid its smooth passage within managerial worlds, such as monitoring and evaluation, results-based management and good practice (Milèn 2001; OECD 2005). Is it working? Is capacity actually being built? What has changed? Measurement brings the problem of definitional clarity to the fore: how to measure, evaluate or enhance something that is poorly defined from the outset? Monitoring and evaluation intensify the hopeful promises of capacity building - transformation becomes the new 'essential ingredient', what capacity building is 'fundamentally about' (Bolger 2000: 2). Scrutinized within a reflexive community of practitioners, then, the latest advice is that there are no recipes, and 'the particulars of [mistakes and successes] must be scrutinised carefully to determine what can be replicated, what can't and why' (UNDP 2009: 35).

If this is how capacity building appears in development and government literatures, what might an anthropological approach to this arena entail? Yarrow and Venkatesan's Differentiating Development (2012) provides a starting point oriented away from antagonistic positions, with a call that anthropologists relinquish 'the belief that anthropologists see more than various development workers because they know more' (2012: 6). They push us instead to attend to what development comes to mean in particular social contexts (Venkatesan 2009) and towards reading development issues 'more squarely in relation to mainstream anthropological concerns' (Yarrow and Venkatesan 2012: 18). Yet despite the differentiation of development that ensues in Yarrow and Venkatesan's broad collection, the concept of capacity building is arguably even more expansive, an easy 'actionable' generic, ready for uptake in any social field. As West notes, capacity development schemes are 'thought to be appropriate for all scales: individuals, organizations, and whole societies' (2016: 71). In the past two decades, capacity building has noticeably decoupled from development agendas and is now valued as a tool of governance, administration, future building and 'progress' in its own right. A bewildering range of sites today present themselves: it can be found in the lexicons of government (Hughes et al. 2010), third sector (Linnell 2003; O'Reilly 2011), religious (McDougall 2013), medical (Kelly 2011; Geissler et al. 2014), environmental (United Nations Environmental Programme [UNEP] 2002) and even familiar academic 
agendas (Danaher et al. 2012; Pfotenhauer et al. 2013, 2016). One of the questions we seek to explore in this special issue is thus how 'capacity building' has been made to 'work' in such diverse settings. What in it carries such broad ranging appeal?

The concept of capacity has a rich history both in Euro-American philosophy and science as well as in anthropological thinking. Invoking 'capacity' means mobilizing a concept borrowed into English from fifteenth-century French's Latinate capacité, meaning the ability to hold. Capacity retains its early definition: we still speak of a reservoir's capacity to hold water, or - for a contemporary reference - the capacity of the internet's material infrastructure to transport data as light, down optic cables (Starosielski 2015). This sense of 'holding' transfers in the familiar usage of capacity as a role one might take - to write in my capacity (a position or role I hold) as chairperson, or friend. Yet we also speak of our personal capacities, often to refer to the ability to learn: 'the mind in ignorance is like a sleeping giant', wrote the English essayist Usher early in the nineteenth century, 'it has immense capacities without the power of using them' (Usher 1824: 328). It is this 'capacity view' of the person - certainly not confined to the $1800 \mathrm{~s}$ - that opens towards intervention, development and potential. It provides a moment in which we might consider the relationship between a capacity that is held (in potentia) and a capacity that is expressed (in actualitas), being brought forth in action.

The history of anthropology is bound up in the conceptualization of capacities, human and otherwise. Readings have wavered between capacities being human universals, and specific capacities being thought absent, not observed or demonstrated by encountered 'others'. A full account of these shifting tides would take us through the significance of how, in early anthropological studies, capacities were attributed, or entire peoples seen to be 'lacking' in one measure or another - belief systems, kinship systems, the presence of 'law'. Such attribution took place against the backdrop of evolutionary and colonial frames informed by moral judgements both of emerging nineteenth-century empirical sciences (Tylor [1871] 2010; Spencer [1855] 1999; Squadrito 2002) and of who and what they studied (Moore 1994). Indeed, West argues that capacity building's ideology smuggles back in the assumptions that there is 'an inherent lack in non-European persons, institutions and social systems' as the driver for technical solutions such as training, structures and audit cultures (West 2016: 72). Though a full historical review of the guises taken by capacity is beyond the scope of this introduction, a historical frame is nonetheless significant for how anthropological accounts position themselves relative to capacities today. Recent work has revived capacity, which continues to hold validity as a route for discussions that would 'bring the nature of the human again to the centre of anthropological deliberation' (Rapport 2005: 2). The resonance we find for capacity building with contemporary work lies, however, not in pursuing it against ideas of human nature, but in the common ground between capacity and 'potential'. In their recent overview of potentiality as an anthropological keyword, Taussig et al. (2013) turned to the Oxford English Dictionary (OED):

1.a A capacity, a possibility; an instance of the latent capacity for development of a person, thing, etc., in which the quality of having potential is embodied. 
Here, potential is itself a capacity, latent or otherwise. Though their article deals with the suffusion of potentiality in the 'contemporary life sciences and medical practice' (Taussig et al. 2013: S3), their breadth of discussion bears upon our interest in capacity. Clear parallels emerge: potential shares with capacity the trait of having been both 'explicit and tacit in the history of anthropology' (2013: S3); it is (unequally) allocated and attributed (2013: S11), giving rise to what the 'right' potentials or capacities might be (2013: S10); and, in what could be a critical reading of capacity building within development discourse, it is concerned with identifying the absences that are preventing the realization of more promising futures, 'even as promises and expectations continually recede on the horizon' (2013: S10). As Taussig et al. note, 'to study potentiality as an empirical object ... can provide a route to renewed reflexivity along with a better understanding of the implications of how people think about human capacities and where they are located' (2013: S7).

The articles in this special issue take off from the following proposal: where in potentiality Taussig et al. find capacities, in capacities we find potentials. Yet if employing potentiality analytically requires an 'anthropological awareness that things could be other than they are' (Taussig et al. 2013: S6), the combination of 'capacity' with 'building' means we must attend to how (and which) capacities can become sites of cultivation or intervention. For the intention of capacity building is precisely to make things other than they are: to transform (UNDP 2009: 5). And with this transformational intent come a broad range of empirical sites. A critical anthropological insight thus obtains: it cannot be known in advance how much of their 'originary' contexts concepts carry within themselves (Wagner 1986) when they are put to use in new settings. We also cannot assume that the 'understandings that produced them' (Strathern 1995: 154) - the priorities, intentions, frameworks - will be borrowed along with the terms themselves. In this way, capacity building's current ubiquity presents a broader challenge for an anthropology of the contemporary (Rabinow et al. 2008) for it carries its hope and insufficiency in uneven and unequal measure.

\section{Overview of themes and arrangement of this collection}

The stimulus for the present collection follows from our discomfort with how capacity building frequently goes unquestioned. Each article addresses a distinct encounter with capacity building, and each presents a variation on what ethnographic attention does for critical analysis. The first set of overarching questions in the collection are ethnographic. What does capacity building look like in practice? Who is involved? How does it gain traction and translate into activities, events and policies? Through this attention, a second set of questions appear: where is capacity thought to inhere? In what or in whom? The third set of questions take up the themes that give this collection its title: the interplay of hope and insufficiency which - we suggest - makes the idea of capacity building persuasive. Following the lead of Miyazaki, whose work on Fijian knowledge practices links philosophical literature on hope with questions of ethnographic method (2004), many scholars have taken up the concept of hope in diverse settings (Mattingly 2010; Pedersen 2012). Our interest in the hope of 'capacity building' lies in its ties to promised futures, and the transformations that will ferry 
participants there. This requires attending to how possibilities and potentials are invoked and mobilized in the pursuit of other ways of doing or being. Where hope may be 'held' and sustained by a range of supporting infrastructures - people, documents, devices - it is rarely measured, and attempts to quantify it sit uneasily with both its intangible expansiveness and its often private character. Capacity building, in contrast, is increasingly implicated in mechanisms of measurement, enmeshed in the politics of governing futures. Conceptualizing capacity through the absences it uses as its starting points, which it identifies in order to 'fill', the articles attend to what capacity building projects intend to remedy. We argue that capacity building 'works' through comparative transformation. It must generate (preferably measurable) insufficiencies that need to be made apparent - an absence that becomes a potential. How, then, is this absence or 'lack' identified, codified and made available, given the potential, for intervention? What is defined as insufficient, and, crucially, by whom? The position and power to make claims specifying absences gives shape to the global currency of capacity building. Critical questions our authors ask include: what becomes of other ways of doing and being, or unwelcome new capacities? What and whose are the standards against which a present is deemed insufficient? What of the capacity to rework projects, to refuse engagement or intervention (Benjamin 2015, 2016)?

These questions result in tensions across the articles in how the authors read capacity building: is it a neocolonialist imposition, or a site for creative reworking on the part of partners or other participants? Are we speaking of the coercive reproduction of familiar power structures, or rather of arenas of re-descriptive hijacking, where projects are repurposed towards new ends by those who are its targets? Furthermore, if we attribute flexible interpretation to those who would build capacity, can those it targets not receive the same credit? The opening article by Kristin LaHatte takes us to the heart of this question. As she shows, in post-earthquake Haiti, 'capacity building' has been naturalized as part of both societal and infrastructural reconstruction. But what is being (re)built? LaHatte shows us projects for the rebuilding of homes, yes, but in her careful analysis of the ways in which capacity building projects intervene with a valuation of certain relationships over others, we find competing notions of capacity building's purpose and potential mapped among those engaged in it. LaHatte introduces us to the Haitian phrase moun pa'm se dra [My people are sheets], which becomes an entry point for her reading of a Haitian 'blanket' of relationships, a sociality understood by local capacity builders to persist through time, into a future when nongovernmental organization (NGO) 'projects' will inevitably dry up. Working with Haitian NGO staff, who both carry out capacity building and remain subjects of it, we see through LaHatte's ethnography how staff select which capacities to cultivate relative to anticipated futures. Such futures do not always match those of their funders, who, in their implicit critique of Haitian social worlds, would see changed persons and a more 'morally appropriate' sociality. Andrea Ballestero takes up this theme of capacities that secure futures in her ethnography of a political device called the 'Water Pact' in Northeast Brazil, an experimental intervention in problems of water scarcity designed to increase a community's 'capacity' to care for water. Ballestero takes us from low reservoirs to public meetings and the index cards of promises through which the pact to manage water is built. It is in these ethnographic moments that conceptual puzzles 
arise: what is the pact if there is nothing to 'belong' to? Ballestero's analysis takes us into new readings of the capacities of the aggregate, highlighting in contrast with the partwhole dynamics of Hobbesian collectives the importance of criteria - selectivity - as a device that allows, in this form of aggregation, for a collective capacity based on moral commitments, not holistic identification.

Similar questions of moral commitment arise in Rachel Douglas-Jones's article, which examines the capacity building work taking place among ethics review committees in the Asia-Pacific region. Explicitly named, capacity building in this setting involves implementing standards formulated in international documents, and, crucially, learning how to demonstrate and evidence adherence to those standards. Having capacity in this setting is fulfilling a pre-defined role. Yet Douglas-Jones goes on to introduce a contrast between ethics as a capacity to be displayed by committees and a capacity for ethics, where trainers focus instead on the qualities of the person. Doing ethics and being ethical are mutually targeted capacities, with capacity building exercises targeting both institutional and personal transformations. Susan Ellison's article also encounters individualized capacity building within initiatives that target specific forms of social relationships in the Bolivian Andes. We learn through her ethnography about a place and people long targeted by international capacity building interventions heavily oriented towards statecraft, bureaucracy and institutions. As capacity building is newly captured by shifting policy modes, recent projects have begun instead to foreground interpersonal habits of speech, deportment and techniques of deliberation seen as necessary for a national, democratic future. Ellison shows that select modes of interacting - regarded by capacity builders as conflictual, militant, resistant - are the target of interventions by so-called conversatorios. In these spaces, the democracy-ready skills of speaking respectfully and listening can be rehearsed, and displace an unwanted, excess 'capacity': the 'unreasonableness' and 'irrationality' that is dangerously present in the union trained citizenry. Ellison formulates the tension precisely: conversatorios 'unmask competing political stakes and expectations of statecitizen relations as sceptical participants revalorize demonized capacities'.

The disjunction in Ellison and Douglas-Jones's articles between the value of new capacities and those they replace is also taken up by Harriet Boulding, drawing on fieldwork with health workers in the Shai-Osudoku district of Ghana. Boulding's approach traces how the definition of capacity building within Ghana's CommunityBased Health Planning and Services programme impacts on health workers' home visits with communities. From the 'blueprints' for improved interaction provided at trainings - laudably oriented towards supporting and growing trusting relationships between rural communities and their health workers - we find contact time coded into 'regular visits' and pre-set questions. As Boulding's ethnography shows, these time slots find no place in the practices of health workers or their communities, resulting in missed sessions or, worse, endangerment of employees. The required questions leave health workers struggling to handle the sociality of home visits, and the politics of talking about reproductive health publicly in close-knit communities. In the equation of capacity building with training activities, then, other 'capacities' are overlooked, with capacity building's definitional rigidity itself becoming the object of the analysis. Viktoryia Kalesnikava’s article similarly stays with these definitional problems, pushing 
us to consider the capacities of categories to sustain the work of two different institutions of social care - SOS Children's Villages and Supportive Housing - aimed at ensuring respectively that children are linked up with families, and the homeless are provided with affordable housing. Her core interest lies in showing ethnographically the capacity of concepts to organize, muddle, order and even break institutions. Drawing on ethnographic and document work in Australia, Russia and the US, she selects moments where divisions between capacities associated with personal and professional domains collapse, or reshape institutional life. Tracing her own biographical transition from trainee anthropologist to trainee social worker, Kalesnikava is in the unique position of being able to draw on her own shifting positions as she takes the reader between fieldwork sites, herself moving between roles.

The transformation of persons is central to Christopher Hewlett's article, which is focused on decades-long 'capacitation' in the Peruvian Amazon. Hewlett examines a Summer Institute of Linguistics (SIL) project originating in the 1950s which had the intention of bringing isolated groups, such as the Amahuaca with whom he worked, into the 'modern world' so they would participate as productive members of Peruvian society. The main mechanism for this was bringing Amahuaca people to 'live together'. The sixty-year timespan of this work produced a wealth of historical documents, earlier ethnographies, life histories and present-day ethnography, which Hewlett channels to show the changing readings of what needs to be transformed, and how the SIL's 'living together' articulates with Amahuaca understandings of bodily transformations and becoming kin. By the time we arrive at Casper Bruun Jensen's article, we are also reaching the limits of the concept of capacity building itself, simply by troubling which capacities are being targeted. Jensen's question is whether capacity building, in spite of its apparently comprehensive mandate, is sufficiently encompassing. His question seems simple: are there capacities that would not fall under capacity building's gaze? How might they appear? He asks this in order to perform a 'lateral' comparison (Gad and Jensen 2016), that is, one intended to test capacity building's conceptual capacities against other contexts - in this case the capacities within the working lives of bureaucrats, nannies and bar workers in the Cambodian capital of Phnom Penh. Here we see different orders of 'growing one's capacity' evidenced, but, as Jensen shows, when laterally compared, they do not fit within 'expected' orders of capacity building's personal, collective or institutional improvement. Thus, by holding up unexpected descriptions of capacity building, we start to see the edges of where capacity building might, despite its breadth, find limits.

\section{The challenge of capacity: intervention, transformation and social change}

This collection brings ethnographic depth to studies of capacity building. It also identifies the wide variety of things that are targeted as 'capacities'. Where Kalesnikava pushes for closer attention to how capacities for care are attributed, Ballestero ponders how a collective capacity can be conceptualized. Where capacities for living together take on double meanings in Hewlett's piece - as both the capacitated bodies of Amazonians and their political participation in national projects - Ellison's conversatorios rapidly 
become contestatorios, rejecting the naivety of 'new', training sanctioned capacities. Each article gives nuance to the ways capacity building is used, demonstrating that the identification of 'capacity', as well as its absence, is a political project, whether these identifications occur in the empirical cases or in our ethnographic descriptions. It therefore remains for us to lay out some of the challenges that exploring capacity building poses for anthropology, and put forward possible strategies for readers who bring it to their ethnographic attention.

We return first to the problem posed at the opening: how do we develop an anthropological approach to concepts that operate across quite distinct settings? The issue is one of shifting conceptual meanings in an era of mobile policy and practice. In this sense, capacity building keeps company with a growing repertoire of conceptpractices such as audit (Strathern 2000; Shore and Wright 2015), ethics (Simpson 2012; Douglas-Jones 2015), collaboration (Konrad 2012; Sariola and Simpson n.d.) and partnership (Jensen and Winthereik 2013), which act upon accepted and desired form(at)s of knowledge and practice. This special issue employs comparison across ethnographic settings as a key technique for drawing contrasts in how capacity building is put to use. The capacity building used by Boulding's community health officers is simply not the same thing as that used by Haitian capacity builders in LaHatte's account, a connection produced through differentiation rather than similitude (Viveiros de Castro 2004). In its ubiquity, capacity building provides an ideal vehicle for experimental cross-regional conversations about the lives of contemporary concepts (Koselleck 2002). As the articles in this issue demonstrate, the purchase of capacity building is not everywhere the same. Therefore, while comparison between settings is generative, so too is comparison within: if a concept seems to proliferate, where, when pushed to its 'limits', does it break down in relation to itself? Described in Jensen's closing article as 'lateral comparison', this move opens new questions at the edges of a conceptual arena. Where capacities might be imagined as infinite, when they are tied to the everyday work of building, as Jensen shows, the term paradoxically has limits. Asking what capacity cannot contain makes visible what will count as the 'right' capacities.

A second challenge lies in how capacity building re-describes the world in its own terms - defining people and situations as having potential, while also constituting them in the present as insufficient, relative to an envisaged future. In Ellison's article, for example, the 'capacity' view of NGO trainers makes it possible to cast existing modes of political interaction as 'unwelcome' capacities, and to replace them with 'good' ones, grown in 'corrective' training sessions. Re-described as an insufficiency, combative debate is made - and made useful - as a justification for imposing other capacities. Yet re-description is also itself a capacity, cultivated particularly within anthropology (Strathern 2005: xiv; Corsín Jiménez 2015). The lesson Ellison's Bolivian interlocutors teach us - through their reactions to capacity building's dismissive re-description of their capacities for debate - is that doing re-description is political work. The opportunity arises, therefore, to turn the lens back - as Hewlett's article does - on accounts of these descriptions and attributions, with a view to critiquing the identification and valuation of some capacities over others. Work by Laura Mentore (n.d.) clearly illustrates that it is not only capacity builders who work conceptually with capacity building. When she 
presents the 'workshop space' of sustainable development and conservation projects taking place in Erefoimo and Surama villages in Guyana, Mentore shows how those who stand to be 'capacitated' rework the intentions of capacity building projects. By attending to how workshop participants recognize the political work that concepts like capacity building do, and seek to redeploy them, Mentore asks us to make careful ethnographic descriptions of capacity building's own re-descriptions.

The final, and possibly most significant challenge for analysis is the way the generic form of capacity building appears self-evident, providing a sense that the forms of change, progress and transformation that it heralds are unremarkable. The articles collected here illustrate that while it carries generic principles and assumptions, it cannot be known in advance how these will be put to work in practice. First, then, it is important to examine how the target of capacity building shapes its enactment. In Ballestero's analysis, for example, focusing on capacity allows for novel theorization around images: the selective aggregate versus holistic membership, a Water Pact open to multiplicity versus one predicated on commonality. Second, ethnographies should explore how these models for change are put into practice. Capacity building not only tries to bring about change, it necessarily carries with it models of how that change can happen and what it will mean, and ethnographic attention is needed at moments of action and inaction alike. Exemplary of this approach is Tess Lea's account of Australian state bureaucracy, through which she shows us how to keep in view the worlds of those who would enact change, seeing how, in swings between 'futility and optimism ... the compulsion to act flourishes at the very point where the ability to act seems annihilated' (Lea 2008: 12). Finally, engaging with models of change analytically requires that we also engage reflexively with the models of change and transformation we bring into anthropological description (Viveiros de Castro 2012; see also Hewlett's article in this issue). If those within the field of capacity building are asking 'who, actually, is building whose capacity?' (Eade 2010: 203), then so too must anthropologists suspend assumptions about the direction and character of change in encounters between those who intend to capacitate and those who stand to be capacitated.

\section{Conclusion}

Capacity building was intended to be transformative (UNDP 2009), yet it is now also itself transformed. In this introduction we have traced a brief genealogy of its emergence, and its expansion into many new arenas. To date, we argue, it has been a blind spot in anthropological accounts. The approaches outlined above arguably extend and support existing anthropological sensitivities that routinely highlight the capacities of others, whether in the form of imaginations, practices or concepts. To bring this sensitivity to encounters with capacity building activities is to retain a non-determinate view of capacities, one that prepares the analyst for the contestations, struggles and ambitions embedded in such projects (Crook 2007), the potential within a given capacity building exercise for its terms to be redrawn (MacIntyre 2015.; Mentore n.d.) and the importance of attending the capacity to refuse (Benjamin 2015.). The articles in this collection all point to disagreements about what will count as a desirable capacity (Lahatte, Douglas-Jones, Ellison), what capacities themselves might be (Hewlett, 
Ballestero, Boulding) or what will trouble the concept of capacity building itself (Kalesnikava, Jensen). By opening up capacity building activities to analysis in these varied ways, we hope to stimulate further empirical engagement with its practices and policies, its hopes and insufficiencies, and also spark discussion of the transformational capacities of anthropology itself.

\section{Acknowledgements}

This collection originated in the 2011 AAA panel 'Legacies of the Past, Promises of the Future: Capacity Building as a Practice of Contemporary Development, Intervention and Governance' sponsored by the Interest Group for the Anthropology of Policy. We thank the participants, particularly Alberto Corsín Jiménez and Sue Wright, our discussants. It was developed with the support of the Wenner-Gren Foundation during a 2015 workshop in Copenhagen. Our thanks to Ruha Benjamin, Martha Macintyre, Laura Mentore, George Mentore, Morten Nielsen, Sebastian Pfotenhauer, Bob Simpson, Paige West and Brit Ross Winthereik for their generous comments and suggestions.

Rachel Douglas-Jones is Associate Professor at the IT University of Copenhagen, where she co-directs the ETHOS Lab. She conducts research on questions of ethics and the governance of science at the intersection of anthropology and science and technology studies through her participation in projects concerned with biomedical data, clinical trial infrastructures and research integrity. Her recent publications include 'A "Good" Ethical Review: Audit and Professionalism in Research Ethics' (Social Anthropology, 2015) and 'Claiming and Knowing the Real' (Journal of the Royal Anthropological Institute, 2016).

Justin Shaffner is a member of the New Centre for Research and Practice. His doctoral research at the University of Cambridge, based in Papua New Guinea with Marind speakers, focused on the experiences of community leaders as they attempted to elicit and maintain productive relations across various global alliances, from regional ritual networks to relations with transnational mining and logging corporations, NGOs and the state. He is editor (with Huon Wardle) of Cosmopolitics: The Collected Papers of the Open Anthropology Cooperative, Volume I (OAC Press, 2017).

\section{Notes}

1. 'Capacity Building: Sarhad University to Provide Academic Support to Police', The Express Tribune, 3 July 2015. http://tribune.com.pk/story/913745/capacity-building-sarhad-university-to-provideacademic-support-to-police/.

2. 'Capacity Building for Resilient Agriculture in the Pacific', Poetcom. http://www.organicpasifika.com/ poetcom/wp-content/uploads/sites/2/2015/02/Youth-and-Organic-Agriculture-for-Resilience.pdf (accessed 24 January 2017).

3. 'Leading Chinese Companies Encouraged to Set 100\% Renewable Energy Goals with RE100', The Climate Group, 2 July 2015. http://www.theclimategroup.org/what-we-do/news-and-blogs/leadingchinese-companies-to-go-100-renewable-in-wake-of-indc-with-new-re100-program/. 


\section{References}

Benjamin, R. 2015. 'Informed Refusal: Salvaging the Capacity to Talk Back'. Paper presented at Hope and Insufficiency: Capacity Building in Ethnographic Comparison, Copenhagen, 20-22 May 2015.

Benjamin, R. 2016. 'Informed Refusal: Toward a Justice-based Bioethics'. Science, Technology and Human Values 41 (6): 967-990. doi:10.1177/0162243916656059.

Black, L. 2003. 'Critical Review of the Capacity Building Literature and Discourse'. Development in Practice 13 (1): 116-120.

Bolger, J. 2000. 'Capacity Development: Why, What and How'. Canadian International Development Agency (CIDA) Policy Branch Capacity Development Occasional Series 1 (1): 1-8.

Cannell, F. (ed.). 2006. The Anthropology of Christianity. Durham, NC: Duke University Press.

Corsín Jiménez, A. 2015. 'The Capacity for Redescription'. In T. Yarrow, M. Candea, C. Trundle and J. Cook (eds), Detachment: Essays on the Limits of Relational Thinking. Manchester: Manchester University Press, 179-197.

Crook, T. 2007. "If You Don't Believe Our Story, At Least Give Us Half of the Money": Claiming Ownership of the Ok Tedi Mine, PNG'. Le Journal de la Société des Océanistes 125: 221-228.

Danaher, P., L. De George-Walker, R. Henderson, K. J. Matthews, W. Midgely, K. Noble, M. A. Tyles and C. H. Arden (eds). 2012. Constructing Capacities: Building Capabilities through Learning and Engagement. Newcastle upon Tyne: Cambridge Scholars Publishing.

Douglas-Jones, R. 2015. 'A “Good” Ethical Review: Audit and Professionalism in Research Ethics'. Social Anthropology 23 (1): 53-67.

Eade, D. 1997. Capacity Building: An Approach to People-Centered Development. London: Oxfam.

Eade, D. 2010. 'Capacity Building: Who Builds Whose Capacity?' In A. Cornwall and D. Eade (eds), Deconstructing Development Discourse: Buzzwords and Fuzzwords. Rugby, UK: Practical Action, 203-215.

Fuduka-Parr, S., C. Lopes and K. Malik. 2002. Capacity for Development: New Solutions to Old Problems. London: Earthscan.

Gad, C. and C. B. Jensen. 2016. 'Lateral Comparisons'. In J. Deville, M. Guggenheim and Z. Hrdličková (eds), Practicing Comparison: Logics, Relations, Collaborations. Mattering Press: Manchester, 189-220.

Geissler, P. W., H. Moore, B. Poleykett, R. J. Prince and N. Tousignant. 2014. Convenors of Making Scientific Capacity in Africa: An Interdisciplinary Conversation. 13-14 June 2014, Centre for Research in the Arts, Social Sciences and Humanities, Cambridge.

Hughes, B., C. Hunt and B. Kondoch. 2010. Making Sense of Peace and Capacity-Building Operations: Rethinking Policing and Beyond. Leiden: Martinus Nijhoff Publishers.

Jensen, C. B. and B. R. Winthereik. 2013. Monitoring Movements in Development Aid: Recursive Partnerships and Infrastructures. Cambridge, MA: MIT Press.

Kaplan, A. 2000. 'Capacity Building: Shifting the Paradigms of Practice'. Development in Practice 10 (3-4): 517-526.

Kelly, J. 2011. State Healthcare and Yanomami Transformations: A Symmetrical Ethnography. Tucson: The University of Arizona Press.

Konrad, M. (ed.). 2012. Collaborators Collaborating: Counterparts in Anthropological Knowledge and International Research Relations. New York: Berghahn Books.

Koselleck, R. 2002. The Practice of Conceptual History: Timing History, Spacing Concepts. Stanford: Stanford University Press. 
Land, T. 1999. 'Conceptual and Operational Issues Arising: Overview Paper'. Paper prepared for the Joint DAC Informal Network/ACBF Workshop on Institutional and Capacity Development, Harare, October.

Lea, T. 2008. Bureaucrats and Bleeding Hearts: Indigenous Health in Northern Australia. Sydney: University of New South Wales Press.

Linnell, D. (ed.). 2003. Evaluation of Capacity Building: Lessons from the Field. New York: Alliance for Non-profit Management.

Lusthaus, C., M.-H. Adrien and M. Perstinger. 1999. 'Capacity Development: Definitions, Issues and Implications for Planning, Monitoring and Evaluation'. Universalia Occasional Paper 35, September.

Macintyre, M. 2015. 'Verbal Sophisms and Problems with Capacity Building'. Paper presented at Hope and Insufficiency: Capacity Building in Ethnographic Comparison, Copenhagen, 20-22 May 2015.

Malik, K. 2002. 'Towards a Normative Framework: Technical Cooperation, Capacities and Development'. In S. Fukuda-Parr, C. Lopes and K. Malik (eds), Capacity for Development: New Solutions to Old Problems. London: Earthscan Publications, no pagination.

Mattingly, C. 2010. The Paradox of Hope: Journeys through a Clinical Borderland. Berkeley: University of California Press.

McDougall, D. 2013. 'Spiritual Capacity? Overseas Religious Missions in RAMSI-Era Solomon Islands'. SSGM Discussion Paper 2013/3. Canberra, ACT: ANU Research School of Pacific and Asian Studies, State, Society and Governance in Melanesia Program.

Mentore, L. n.d. 'Capacity Building Workshops in Indigenous Amazonia: The Virtualism of the New Middle Grounds'. Unpublished.

Merry, S. E. 2015. 'Comment on C. Shore and S. Wright, "Audit Culture Revisited: Rankings, Ratings and the Reassembling of Society". Current Anthropology 56 (3): 421-444.

Milèn, A. 2001. 'What Do We Know about Capacity Building? An Overview of Existing Knowledge and Good Practice'. Geneva: Department of Health Service Provision, World Health Organization (WHO).

Miyazaki, H. 2004. The Method of Hope: Anthropology, Philosophy and Fijian Knowledge. Stanford: Stanford University Press.

Morgan, P. and A. Qualman. 1996. 'Institutional and Capacity Development: Results-Based Management and Organizational Performance'. Paper prepared for the Canadian International Development Agency.

Moore, H. L. 1994. A Passion for Difference: Essays in Anthropology and Gender. Indiana: Indiana University Press.

O’Reilly, K. 2011. 'Building Capacity, Extracting Labour: The Management of Emotion in NGOs'. Paper presented at 'Traces, Tidemarks and Legacies', 110th annual meeting of the American Anthropological Association, Montreal, 16-20 November.

OECD (Organisation for Economic Co-operation and Development). 1996. 'Shaping the 21st Century: The Contribution of Development Cooperation'. Paris: OECD.

OECD (Organisation for Economic Co-operation and Development). 2005. 'Living up to the Capacity Development Challenge: Lessons and Good Practice'. Draft. Paris: Learning Network on Capacity Development, Development Assistance Committee Network on Governance.

OECD (Organisation for Economic Co-operation and Development). 2008. 'The Accra Agenda for Action'Paris: OECD.

Ong, A. and S. Collier. 2005. Global Assemblages: Technology, Politics and Ethics as Anthropological Problems. Oxford: Blackwell Publishing

Pedersen, M. A. 2012. 'A Day in the Cadillac: The Work of Hope in Urban Mongolia'. Social Analysis 56 (2): 1-16. 
Pfotenhauer, S., D. Roos and D. Newman. 2013. 'Collaborative Strategies for Innovation Capacity-Building: A Study of MIT's International Partnerships'. In P. Teirlinck, F. de Beule and S. Kelchtermans (eds), Proceedings of the 8th European Conference on Innovation and Entrepreneurship. Brussels: Belgium, 498-506.

Pfotenhauer, S., D. Wood, D. Roos and D. Newman. 2016. 'Architecting Complex International Science, Technology and Innovation Partnerships (CISTIPs): A Study of Four Global MIT Collaborations'. Technological Forecasting and Social Change 104: 38-56. doi:0.1016/j. techfore.2015.12.006.

Rabinow, P., G. E. Marcus, J. D. Faubion and T. Rees. 2008. Designs for an Anthropology of the Contemporary. Durham, NC: Duke University Press.

Rapport, N. (ed.). 2005. Human Nature as Capacity: Transcending Discourse and Classification. Oxford: Berghahn Books.

Robbins, J. and M. Engelke. 2010. 'Global Christianity, Global Critique'. Special Issue of South Atlantic Quarterly 109 (4).

Robinson, S. A. and P. Cox. 1998. 'Participatory Evaluation in Human Resource Development: A Case Study for Southeast Asia'. In E. T. Jackson and Y. Kassam (eds), Knowledge Shared: Participatory Evaluation in Development Cooperation. West Hartford, CT: Kumarian Press, 122-150.

Roche, C. 1997. 'Preface'. In D. Eade (ed.), Capacity Building: An Approach to People-Centered Development. London: Oxfam, v-vi.

Sariola, S. and B. Simpson. n.d. Research as Development: Biomedical Research, Ethics and Collaboration in Sri Lanka. Unpublished.

Shore, C. and S. Wright. 2015. 'Audit Culture Revisited: Rankings, Ratings and the Reassembling of Society'. Current Anthropology 56 (3): 421-444.

Simpson, B. 2012. 'Building Capacity: A Sri Lankan Perspective on Research, Ethics and Accountability'. In M. Konrad (ed.), Collaborators Collaborating. New York: Berghahn Books, 147-164.

Spencer, H. [1855] 1999. The Principles of Psychology. London: Bloomsbury USA Academic.

Squadrito, K. 2002. 'Locke and the Dispossession of the American Indian'. In J. K. Ward and T. L. Lott (eds), Philosophers on Race: Critical Essays. Oxford: Blackwell Publishing, 101-125.

Starosielski, N. 2015. The Undersea Network. Durham, NC: Duke University Press.

Strathern, M. 1995. 'The Nice Thing about Culture is Everyone Has It'. In M. Strathern (ed.), Shifting Contexts: Transformations in Anthropological Knowledge. London: Routledge, 153-170.

Strathern, M. (ed.). 2000. Audit Culture: Anthropological Studies in Accountability, Ethics and the Academy. London: Routledge.

Strathern, M. 2005. 'Prologue. In M. S. Mosko and F. H. Damon (eds), On the Order of Chaos: Social Anthropology and the Science of Chaos. New York: Berghahn Books, xii-xv.

Taussig, K.-S., K. Hoeyer and S. Helmreich. 2013. 'The Anthropology of Potentiality in Biomedicine: An Introduction to Supplement 7'. Current Anthropology 54 (S7): S3-S14.

Tylor, E. B. [1871] 2010. Primitive Culture: Researches into the Development of Mythology, Philosophy, Religion, Art, and Custom. Cambridge: Cambridge University Press.

UNDP (United Nations Development Programme). 1998. 'Capacity Assessment and Development in a Systems and Strategic Management Context'. MDGB Technical Advisory Paper 3.

UNDP (United Nations Development Programme). 2003. 'Ownership, Leadership and Transformation: Can We Do Better for Capacity Development?' London: Earthscan Publications.

UNDP (United Nations Development Programme). 2009. 'Capacity Development: A UNDP Primer'. New York: United Nations Development Programme. 
UNEP (United Nations Environmental Programme). 2002. 'Capacity Building for Sustainable Development: An Overview of UNEP Environmental Capacity Development Activities'. New York: United Nations Environmental Programme.

UNMDG (United Nations Millennium Development Goals). 2013. 'United Nations Millennium Development Goals'. http://www.un.org/millenniumgoals/.

Usher, G. 1824. 'Thoughts on Human Capacity'. In V. Knox (ed.), Elegant Extracts: Or Useful and Entertaining Passages in Prose. London: JG Barnard, 328.

Venkatesan, S. 2009. Craft Matters: Artisans, Development and the Indian Nation. Hyderabad: Orient Blackswan.

Viveiros de Castro, E. 2004. 'Perspectival Anthropology and the Method of Controlled Equivocation'. Tipiti 2: 3-22.

Viveiros de Castro, E. 2012. “Transformação” na antropologia, transformação da "antropologia"' [Tranformation in Anthropology, Transformation of Anthropology]. Mana 18 (1): 151-171.

Wagner, R. 1986. Symbols that Stand for Themselves. Chicago: University of Chicago Press.

West, P. 2016. Dispossession and the Environment: Rhetoric and Inequality in Papua New Guinea. New York: Columbia University Press.

Yarrow, T. and S. Venkatesan. 2012. 'Anthropology and Development: Critical Framings'. In T. Yarrow and S. Venkatesan (eds), Differentiating Development: Beyond an Anthropology of Critique. Oxford: Berghahn Books, 1-20. 